\title{
A SYSTEM APPROACH FOR OPTIMIZING OF PARAMETERS OF THE PROPOSED MARITIME CONTAINER PORT IN ŚWINOUJŚCIE
}

\section{SYSTEMOWE PODEJŚCIE DO OPTYMALIZACJI PARAMETRÓW PROJEKTOWANEGO MORSKIEGO PORTU KONTENEROWEGO W ŚWINOUJŚCIU}

\begin{abstract}
Stanisław Gucma
Akademia Morska w Szczecinie

Abstract: The article presents specially developed methods for optimizing of parameters of the proposed maritime container port in Świnoujście with planned transshipment capacity of 1.5-million TEU intended for handling container vessels up to $400 \mathrm{~m}$ length. The methods have been developed based on a system approach for the proposed maritime waterways.
\end{abstract}

Keywords: maritime container port, maritime waterways

Streszczenie: $W$ artykule zaprezentowano specjalnie opracowane metody optymalizacji parametrów projektowanego morskiego portu kontenerowego w Świnoujściu o planowanej zdolności przeładunkowej 1,5mln TEU przeznaczonego do obstugi kontenerowców o dtugości do 400m. Metody te zostały opracowane $w$ oparciu o systemowe podejście do projektowania morskich dróg wodnych.

Stowa kluczowe: morski port kontenerowy, drogi wodne 
System approach to optimization parameters of the designed marine port...

Systemowe podejście do optymalizacji parametrów projektowanego morskiego...

\section{SYSTEMOWE PODEJŚCIE DO OPTYMALIZACJI \\ PARAMETRÓW PROJEKTOWANEGO MORSKIEGO PORTU KONTENEROWEGO W ŚWINOUJŚCIU}

\section{Wprowadzenie}

Koncepcja budowy terminalu kontenerowego w Świnoujściu opracowana przez Zarząd Morskich Portów Szczecin i Świnoujście S.A. określa następujące założenia:

- Terminal kontenerowy w Świnoujściu powinien przeładowywać w pierwszym etapie budowy $0,5 \mathrm{mln}$. TEU (kontenerów 20 stopowych) rocznie, a docelowo $1,5 \mathrm{mln}$. TEU rocznie.

- Dowóz i wywóz kontenerów do/z terminala będzie odbywał się przy wykorzystaniu następujących środków transportu:

- samochodowy - po uruchomieniu drogi szybkiego ruchu S3 (w trakcie realizacji);

- kolejowy - po modernizacji nadodrzańskiej magistrali kolejowej (w trakcie realizacji).

- wodny - po modernizacji Odrzańskiej Drogi Wodnej docelowo do IV klasy żeglowności, a w bieżącej pięciolatce do III klasy żeglowności (obecnie IV klasa - do kanału Hawela).

- Terminal kontenerowy w Świnoujściu powinien być zlokalizowany na wschód od Portu Zewnętrznego w Świnoujściu uwzględniając strefy zagrożeń związanych z manewrowaniem i rozładunkiem gazowców LNG [2,7,3].

Terminal kontenerowy w Świnoujściu powinien mieć możliwości obsługi kontenerowców oceanicznych o ładowności do 20.000 TEU i feederów do 10.000 TEU.

Uwzględniając powyższe założenia określono jego najkorzystniejszą wstępną lokalizację przedstawioną na rys. 1 [3]. Planowana wielkość maksymalnych statków obsługiwanych $\mathrm{w}$ terminalu kontenerowym o głębokości podejścia $\mathrm{h}=14,5 \mathrm{~m}$ to kontenerowiec o ładowności 18.000 TEU, nośności 200.000 DWT, długości $\mathrm{L}_{\mathrm{c}}=400 \mathrm{~m}$, szerokości $\mathrm{B}=60,0 \mathrm{~m}$ i zanurzeniu $\mathrm{T}=13,0 \mathrm{~m}$.

W przypadku planowanego pogłębienia podejścia do Świnoujścia zanurzenie kontenerowców można zwiększyć do 14,5m. poprzez:

- pogłębienie północnego toru podejściowego do pławy „N-1" na $h=16,5 \mathrm{~m} \div 17,0 \mathrm{~m}$;

- pogłębienie toru podejściowego od pławy „N-1” (43,2km) do główek portu $h=16,5 \mathrm{~m}$; 
Należy przy tym zaznaczyć, że zdecydowana większość „maksymalnych” kontenerowców wchodzi na Bałtyk z zanurzeniem mniejszym niż 13,0 m, co wynika $\mathrm{z}$ warunków eksploatacji tego typu statków [9].

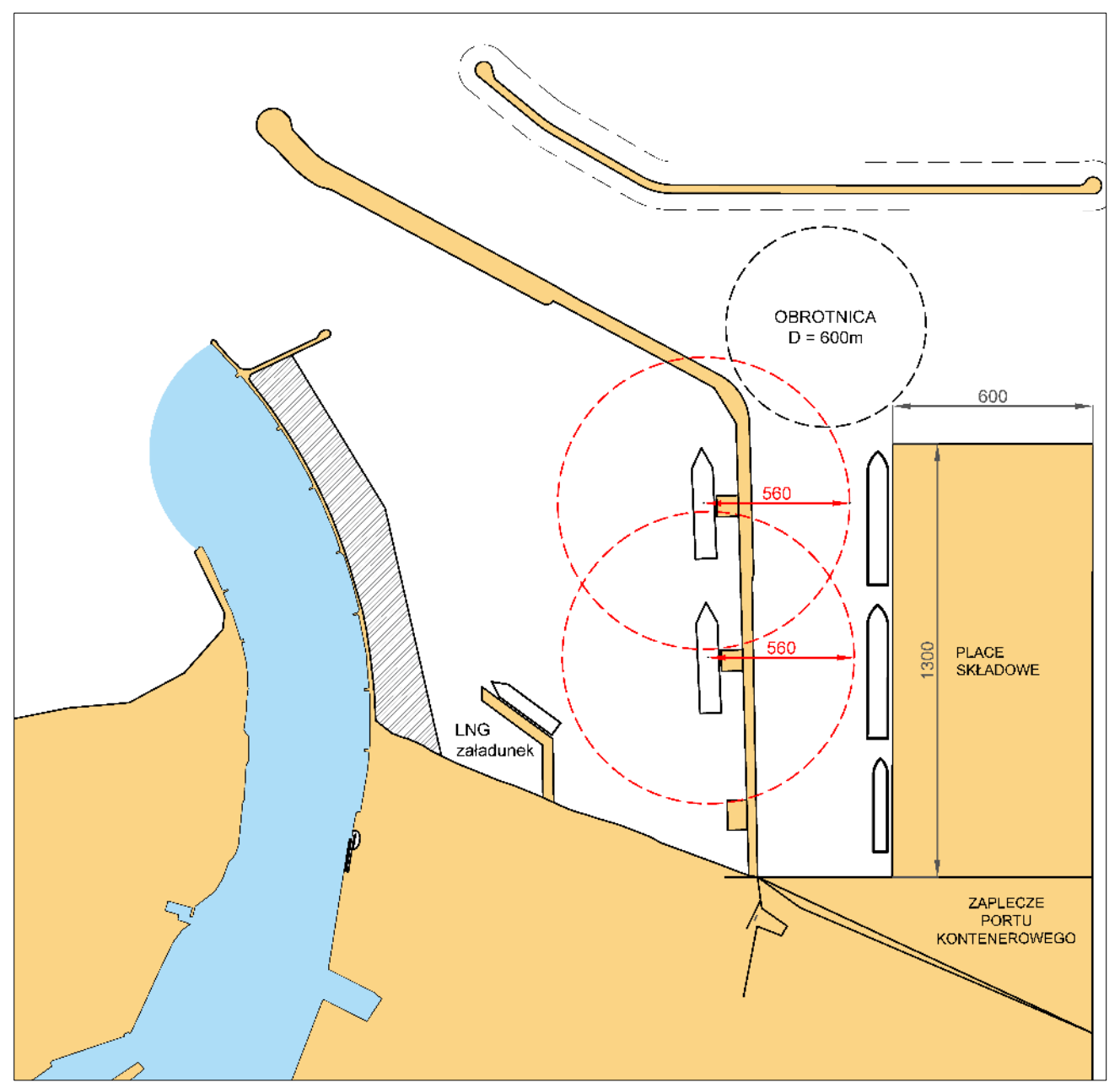

Rys. 1 Terminal kontenerowy zlokalizowany na wschód od Portu Zewnętrznego Świnoujście

Minimalna bezpieczna głębokość toru podejściowego do Portu Świnoujście dla „maksymalnych” kontenerowców o maksymalnym zanurzeniu $T=13,0 \mathrm{~m}$ poruszających się prędkościami $V=8 \div 10$ węzłów wynosi $h=14,5 \mathrm{~m} \mathrm{[4]}$.

Analiza batymetrii podejściowego toru wodnego portu Świnoujście jednoznacznie wskazuje na możliwość wprowadzenia ruchu dwukierunkowego dla „maksymalnych” kontenerowców na odcinku od pławy „N-1” (43,2km) - 
System approach to optimization parameters of the designed marine port... Systemowe podejście do optymalizacji parametrów projektowanego morskiego...

kotwicowisko $\mathrm{Nr} 3$ do pary pław „9-10” (13,6km). Na tym odcinku tor wodny w północnej części przechodzi przez akwen o naturalnych głębokościach powyżej $14,5 \mathrm{~m}$, a w południowej jego części przechodzi przez akweny o głębokościach 13,5 $\mathrm{m} \div 14,5 \mathrm{~m}$, wymagających niewielkich prac pogłębiarskich (Rys. 2).

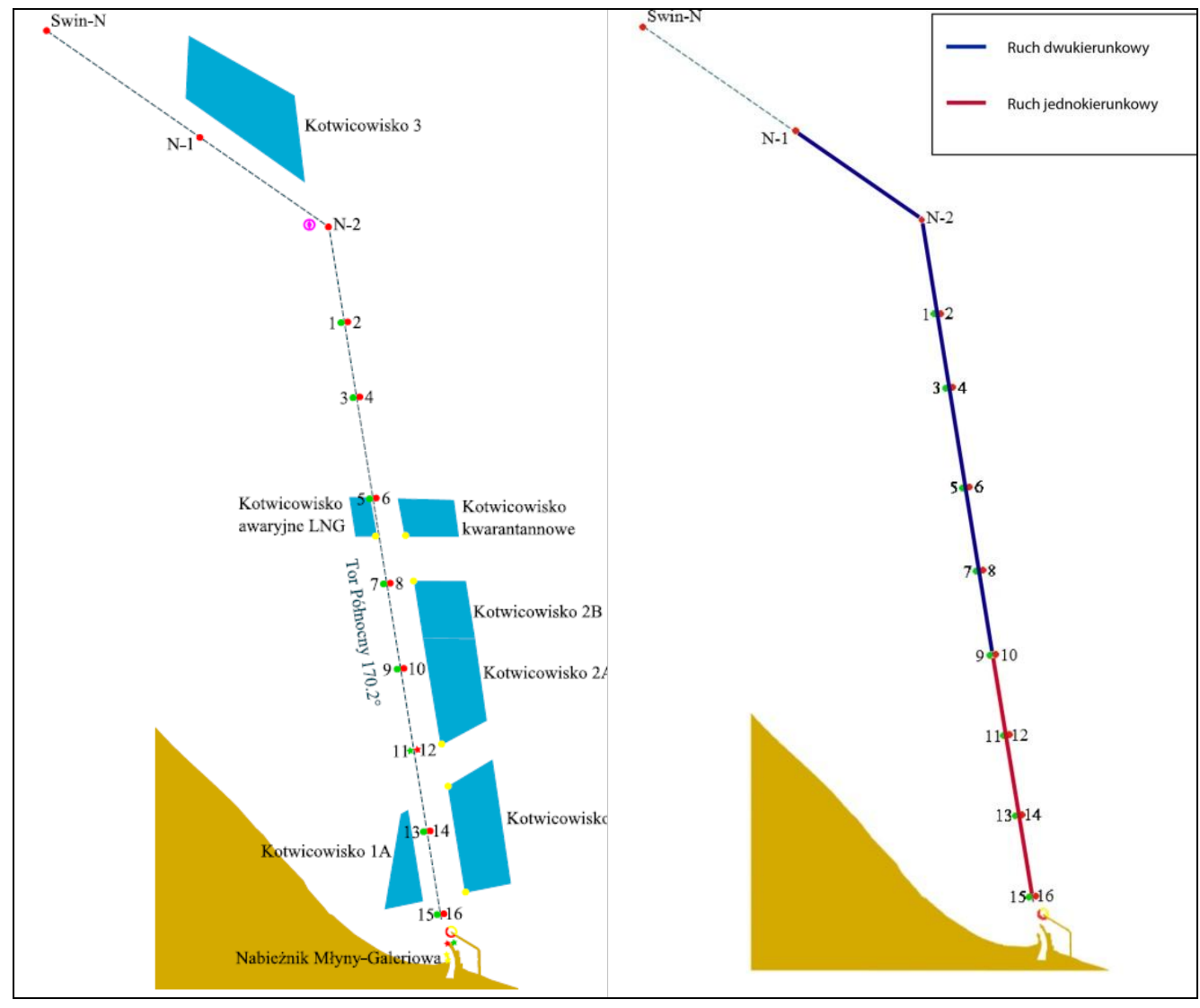

Rys. 2 Schemat toru podejściowego do Świnoujścia

z zaznaczonymi kotwicowiskami, systemem oznakowania nawigacyjnego i planowanym podziatem na odcinki o ruchu jedno- i dwu-kierunkowym

$\mathrm{Na}$ odcinku od pary pław ,9-10” (13,6km) do pary pław „15-16” $(1,7 \mathrm{~km})$ „maksymalne” kontenerowce (oceaniczne i feedery) muszą poruszać się w ruchu jednokierunkowym. Tor na tym odcinku dla „maksymalnych” feederów $\left(L_{c}=320 \mathrm{~m}\right)$ nie musi być przebudowywany, natomiast dla kontenerowców oceanicznych $\left(L_{c}=400 \mathrm{~m}\right)$ wymaga pewnej korekty.

Równoległe do rozwiązań morskiej części terminalu kontenerowego rozwiązania technologiczne części lądowej pozwoliły na określenie parametrów nabrzeży, placów składowych, dróg dojazdowych i linii kolejowych [1]. 


\section{Port jako system złożony $z$ różnego rodzaju dróg wodnych}

Systemy morskich dróg wodnych i warunki bezpiecznej eksploatacji statków tam manewrujących są różnie definiowane $\mathrm{w}$ zależności od rodzaju drogi wodnej i wykonywanych manewrów [4].

Z powyższego względu systemy morskich dróg wodnych można pogrupować na:

- tor wodny (manewr przejścia torem) i wejście do portu (manewr wejścia do portu);

- obrotnica (manewr obracania) i kotwicowisko (manewr kotwiczenia);

- basen portowy (manewr podejścia do nabrzeża) i śluza (manewr wejścia, wyjścia, cumowania).

$\mathrm{W}$ każdej $\mathrm{z}$ grup inaczej definiowany jest podsystem akwenu oraz warunki bezpiecznej eksploatacji statków i w rezultacie stosowane są różne metody ich projektowania.

Istnieją również systemy złożone $\mathrm{z}$ różnego rodzaju dróg wodnych takie jak porty morskie. Typowy port morski składa się z następujących dróg wodnych:

- kotwicowisko;

- tor wodny (podejście do portu);

- wejście do portu;

- basen portowy w skład, którego wchodzi:

- obrotnica;

- podejście do nabrzeży;

- nabrzeża.

System morskich dróg wodnych $\mathrm{w}$ rodzaju toru wodnego, kotwicowiska, wejścia do portu lub obrotnicy definiują parametry jego dwóch elementów (podsystemów). Dwa elementy tego systemu są funkcją warunków bezpiecznej eksploatacji statków tam manewrujących [4].

$$
\left[\begin{array}{l}
\mathbf{A}_{\mathrm{i}}^{\mathrm{t}} \\
\mathbf{N}_{\mathrm{i}}^{\mathrm{t}}
\end{array}\right]=\mathrm{F}\left(\mathbf{W}_{\mathrm{i}}^{\mathrm{t}}\right)
$$

gdzie:

$\mathbf{W}_{\mathrm{i}}^{\mathrm{t}}-$ warunki bezpiecznej eksploatacji statków na torze wodnym (i-ty odcinek);

$\mathbf{A}_{\mathrm{i}}^{\mathrm{t}}-$ podsystem akwenu (toru wodnego);

$\mathbf{N}_{\mathrm{i}}^{\mathrm{t}}-$ podsystem nawigacyjny toru wodnego.

System morskich dróg wodnych takich jak basen portowy definiują parametry jego elementów (podsystemów). Trzy elementy takiego systemu dróg wodnych są funkcją warunków bezpiecznej eksploatacji „statku maksymalnego”. 
System approach to optimization parameters of the designed marine port... Systemowe podejście do optymalizacji parametrów projektowanego morskiego...

W związku z tym system $i$-tego nabrzeża $\mathrm{w}$ basenie portowym można przedstawić następująco [4]:

$$
\left[\begin{array}{l}
\mathbf{A}_{\mathrm{i}}^{\mathrm{p}} \\
\mathbf{K}_{\mathrm{i}}^{\mathrm{p}} \\
\mathbf{N}_{\mathrm{in}}^{\mathrm{p}}
\end{array}\right]=f\left(\mathbf{W}_{\mathrm{i}}^{\mathrm{p}}\right)
$$

gdzie:

$\mathbf{W}_{\mathrm{i}}^{\mathrm{p}}-$ zbiór warunków bezpiecznej eksploatacji „statku maksymalnego" podchodzącego do $i$-tego nabrzeża.

$\mathbf{A}_{\mathrm{i}}^{\mathrm{p}}-$ podsystem akwenu portowego;

$\mathbf{K}_{\mathrm{i}}^{\mathrm{p}}$ - podsystem nabrzeża i jego wyposażenie;

$\mathbf{N}_{\mathrm{i}}^{\mathrm{p}}$ - podsystem nawigacyjny określania położenia i prędkości statku w basenie portowym.

Warunki bezpiecznej eksploatacji statków w systemie portowych dróg wodnych dzielą się na trzy różnie definiowane grupy przy czym wejście do portu zakwalifikowane jest do drugiej lub trzeciej grupy w zależności od wykonywanego manewru wejścia samodzielnego lub w asyście holownika. Są to:

- Kotwicowisko.

- Tor wodny i wejście do portu (bez asysty holowników).

- Obrotnica, basen portowy i wejście do portu (z asystą holowników).

Zbiór warunków bezpiecznej eksploatacji „statków maksymalnych” na kotwicowisku:

$$
\mathbf{W}^{k}=\left[L_{c}, B, T, \mathbf{H}^{k}\right]
$$

natomiast zbiór dopuszczalnych warunków hydrometeorologicznych kotwiczenia statku:

gdzie:

$$
\mathbf{H}^{k}=\left[\Delta h^{k}, V_{w}^{k}, V_{p}^{k}\right]
$$

$\Delta h^{k}-$ dopuszczalne obniżenie poziomu zwierciadła wody na kotwicowisku dla „statku maksymalnego";

$V_{w}^{k} \quad$ - dopuszczalna prędkość wiatru podczas kotwiczenia „statku maksymalnego”;

$V_{p}^{k} \quad$ - dopuszczalna prędkość prądu podczas kotwiczenia „statku maksymalnego”;

$L_{c} \quad$ - długość całkowita statku „maksymalnego”;

B - szerokość statku „maksymalnego";

$T$ - zanurzenie statku „maksymalnego”. 
Zbiór warunków bezpiecznej eksploatacji statku przechodzącego torem wodnym:

$$
\mathbf{W}^{t}=\left[t_{y p}, L_{c}, B, T, H_{s t}, V_{i}, \mathbf{H}_{i}^{t}\right]
$$

natomiast zbiór dopuszczalnych warunków hydrometeorologicznych przejścia torem:

$$
\mathbf{H}^{t}=\left[d / n, \Delta h^{t}, V_{w}, V_{p}\right]
$$

gdzie:

$\Delta h^{t}$ - dopuszczalne obniżenie poziomu zwierciadła wody na torze dla ,statku maksymalnego";

$V_{w}$ - dopuszczalna prędkość wiatru dla „statku maksymalnego” wchodzącego do portu;

$V_{p}$ - dopuszczalna prędkość prądu dla ,statku maksymalnego" wchodzącego do portu.

Zbiór warunków bezpiecznej eksploatacji obracania i cumowania „statków maksymalnych":

$$
\mathbf{W}^{p}=\left[t_{y p}, L_{c}, B, T, H_{s t}, F, M, M_{s t}, n_{h}, U_{h}, \mathbf{H}^{p}\right]
$$

natomiast zbiór dopuszczalnych warunków hydrometeorologicznych manewrów obracania i cumowania:

$$
\mathbf{H}^{p}=\left[d / n, \Delta h^{p}, V_{w}, V_{p}\right]
$$

gdzie:

$H_{s t} \quad-\quad$ wysokość statku „maksymalnego";

$F \quad-\quad$ boczna powierzchnia nawiewu statku „maksymalnego”;

$M \quad$ - moc napędu głównego statku „maksymalnego";

$M_{s t} \quad$ - moc sterów strumieniowych statku ,maksymalnego";

$n_{h} \quad-\quad$ ilość holowników w asyście;

$U_{h} \quad-\quad$ sumaryczny uciąg na palu holowników w asyście;

$\Delta h^{p} \quad-$ dopuszczalne obniżenie zwierciadła wody $\mathrm{w}$ basenie portowym dla „statku maksymalnego".

Określając bezpieczne warunki eksploatacji statków w typowym porcie należy zwrócić uwagę że w systemie portowych dróg wodnych parametry ,statku maksymalnego" $L, B, T, H_{s t}$ są jednakowe dla wszystkich jego odcinków (grup). Dopuszczalne prędkości wiatru $V_{w}$ i prądu $V_{p}$ są jednakowe dla manewrów przejścia torem, obracania oraz cumowania i różnią się od manewrów kotwiczenia gdzie wartości te są znacznie większe. 
System approach to optimization parameters of the designed marine port...

Systemowe podejście do optymalizacji parametrów projektowanego morskiego...

\section{Systemowe podejście do optymalizacji parametrów projektowanego portu kontenerowego}

Optymalizacja parametrów projektowanego portu kontenerowego w Świnoujściu wykonywana jest w dwóch częściach:

1) Optymalizacja parametrów toru podejściowego do terminalu (portu kontenerowego w Świnoujściu od pławy N-2 (35,6km toru) do pary pław „15” - „16” (2,1km toru). Tor ten będzie dostosowywany do warunków bezpiecznej eksploatacji kontenerowców o długości $\mathrm{L}_{\mathrm{c}}=400 \mathrm{~m}$.

2) Optymalizacja parametrów projektowanego terminalu (portu) kontenerowego w Świnoujściu w skład którego wchodzą:

- wejście do portu od pary pław „15” - „16” (2,1km toru),

- obrotnica,

- podejście do nabrzeży,

- nabrzeża terminalu kontenerowego.

Przy projektowaniu parametrów podejściowego toru wodnego do portu Świnoujście pozwalającego na bezpieczne przejście kontenerowców o długości $\mathrm{L}_{\mathrm{c}}=400 \mathrm{~m}$, przyjęto następujące założenia wynikające $\mathrm{z}$ wstępnego etapu projektowania:

- tor wodny składa się z dwóch odcinków o ruchu jednokierunkowym od 2,1 km do około $14 \mathrm{~km}$ toru i ruchu dwukierunkowym od około $14 \mathrm{~km}$ toru do $35,6 \mathrm{~km}$ toru.

- dla każdej pory doby i dla każdej widzialności musi być dostępne minimum dwa systemy określenia pozycji z wymaganą dokładnością.

Optymalizacja parametrów podejściowego toru wodnego do Świnoujścia jako systemu drogi wodnej przeprowadzana jest w dwóch etapach:

Etap I - Optymalizacja szerokości jednokierunkowego i dwukierunkowego toru wodnego oraz parametrów ich oznakowania nawigacyjnego gdzie funkcja celu jest minimalizacja kosztów przebudowy toru i jego oznakowania:

$$
\mathrm{Z}=(\mathrm{A}+\mathrm{N}) \rightarrow \min
$$

przy ograniczeniu wynikającym $\mathrm{z}$ podstawowego warunku bezpieczeństwa nawigacji:

$$
\overbrace{p(x, y) \in \mathbf{D}(t)} \begin{array}{r}
\mathbf{d}_{i k z(1-\alpha)} \subset \mathbf{D}_{\mathbf{i}}(t) \\
h_{x y}(t) \geq T_{x y}(t)+\Delta_{x y(1-\alpha)}
\end{array}\}
$$


gdzie:

$\mathbf{D}_{\mathbf{i}}(t) \quad$ - dostępny akwen żeglugowy na $i$-tym odcinku drogi wodnej (spełniony warunek bezpiecznej głębokości w momencie $t$ );

$\mathbf{d}_{i k z(1-\alpha)}-$ bezpieczny obszar manewrowy $k$-tego statku wykonywującego manewr na $i$-tym odcinku drogi wodnej $\mathrm{w} z$-tych warunkach nawigacyjnych określony na poziomie ufności $1-\alpha$,

Z $\quad$ - koszt budowy systemu dróg wodnych;

A $\quad-$ koszt budowy (przebudowy) drogi wodnej;

$N \quad-$ koszt budowy podsystemu określania położenia statku (systemów nawigacyjnych);

Etap II - Optymalizacja długości odcinka dwukierunkowego toru wodnego, gdzie funkcją celu jest minimalizacja kosztów budowy i eksploatacji systemu morskich dróg wodnych uwzględniający koszty związane $\mathrm{z}$ opóźnieniami statków poszczególnych grup wielkościowych dla prognozowanych intensywności ruchu, którą można zapisać następująco:

$$
Z=\left(A_{b}+A_{e}+N_{b}+N_{e}+K_{s}\right) \rightarrow \min
$$

gdzie:

$A_{b}$ - roczna amortyzacja drogi wodnej (koszty budowy podzielone na 50-letni okres amortyzacji);

$A_{e}$ - roczne koszty eksploatacyjne drogi wodnej;

$N_{b}$ - roczna amortyzacja nieautonomicznych systemów nawigacyjnych (koszty budowy systemów nawigacyjnych podzielone na 15-letni okres amortyzacji);

$N_{e}$ - roczne koszty eksploatacji nieautonomicznych systemów nawigacyjnych;

$K_{s}$ - roczne koszty opóźnień statków korzystających z projektowanej drogi wodnej;

Okresy amortyzacji wynikają z tego, że drogi wodne projektowane są zazwyczaj na 50-letni okres eksploatacji, natomiast statki na 15-letni okres eksploatacji. W okresie 50-letniej eksploatacji drogi wodnej są kilkakrotnie modernizowane, co związane jest głównie $\mathrm{z}$ wprowadzeniem coraz doskonalszych systemów nawigacyjnych [Gucma S. 2001].

Roczne koszty opóźnień statków korzystających z określonego realnego wariantu budowy projektowanej drogi wodnej określa się według następującej zależności:

$$
K_{s}=\sum_{l=1}^{n} l_{l} \cdot t_{l} \cdot k_{l}
$$

gdzie:

$t_{l}$ - średni czas opóźnienia statku $l$-tej grupy;

$l_{l}$ - prognozowana ilość statków $l$-tej grupy korzystających $\mathrm{w}$ roku z projektowanej drogi wodnej;

$k_{l}$ - jednostkowe koszty opóźnienia statku $l$-tej grupy. 
System approach to optimization parameters of the designed marine port...

Systemowe podejście do optymalizacji parametrów projektowanego morskiego...

Określenie rocznych kosztów opóźnień statków korzystających z realnego wariantu budowy projektowanej drogi wodnej wykonywane jest metodą symulacji komputerowej strumieni ruchu statków.

Terminal (port) kontenerowy w Świnoujściu jest złożonym systemem morskich dróg wodnych składającym się z wejścia do portu, obrotnicy i podejść do nabrzeży. Optymalizacja systemu morskich dróg wodnych przeprowadzana jest przy określeniu parametrów podstawowych elementów budowanego lub przebudowywanego systemu (podsystem akwenu i podsystem nawigacyjny). Parametry elementów systemu morskich dróg wodnych są funkcją projektowanych (założonych) warunków bezpiecznej eksploatacji statku.

Funkcją celu w zadaniach optymalizacji parametrów systemu morskich dróg wodnych jest minimalizacja kosztów budowy (modernizacji) elementów systemu drogi wodnej oraz koszt eksploatacji tych podsystemów.

Przyjmując powyższe założenia, funkcję celu optymalizacji parametrów dróg wodnych można zapisać $\mathrm{w}$ postaci $[4,5]$ :

$$
Z=\left(A_{1}+A_{2}+N_{1}+N_{2}+S\right) \rightarrow \min
$$

przy ograniczeniu wynikającym $\mathrm{z}$ podstawowego warunku bezpieczeństwa nawigacji, gdzie:

$Z$ - koszt budowy i eksploatacji systemu dróg wodnych;

$A_{1}$ - koszt budowy (przebudowy) drogi wodnej;

$A_{2}-$ koszt eksploatacji drogi wodnej;

$N_{1}-$ koszt budowy podsystemu określania położenia statku (systemów nawigacyjnych);

$N_{2}-$ koszt eksploatacji systemów nawigacyjnych;

$S$ - koszty eksploatacji statku związane z przejściem drogi wodnej (oczekiwanie na przejście, pilotaż, asysta holownika, itp.);

W przypadku morskich dróg wodnych o stałej głębokości $\left(h_{x y}=\right.$ const $)$ funkcję celu można zapisać w postaci:

$$
\mathrm{Z}=\mathrm{F}\left(\mathbf{D}_{\mathbf{i}}\right) \rightarrow \min
$$

przy ograniczeniu:

$$
\mathbf{d}_{\mathbf{i}(1-\alpha)} \subset \mathbf{D}_{\mathbf{i}}(t)
$$

Optymalizacja parametrów terminalu (portu) kontenerowego w Świnoujściu przeprowadzana jest przy wykorzystaniu symulacyjnej metody optymalizacji dróg wodnych [4]. 


\section{Wnioski}

W artykule przedstawiono metody optymalizacji parametrów projektowanego morskiego portu kontenerowego w Świnoujściu o planowanej zdolności przeładunkowej 1,5 mln TEU, do którego będą mogły zawijać kontenerowce oceaniczne o długości 400m.

Zaprezentowane metody optymalizacji opracowano w oparciu o systemowe podejście do projektowania morskich dróg wodnych. Przedstawione metody optymalizacji dotyczą podejściowych torów wodnych oraz parametrów akwenów portowych składających się z wejścia do portu, obrotnicy i basenów portowych. Są to unikalne metody umożliwiające optymalne określenie parametrów dróg wodnych zapewniających odpowiedni poziom bezpieczeństwa nawigacji.

\section{Literatura}

[1] Brinkmann B. (2011): Operations systems of container terminals: a compendious overview. Handbook of terminal planning. Springer New York, 2011, pp. 25-39.

[2] Docelowa zabudowa portu zewnętrznego w Świnoujściu - analiza nawigacyjna. Praca naukowo-badawcza pod kierunkiem S. Gucmy, zlecona przez Zarząd Morskich Portów Szczecin i Świnoujście. Akademia Morska w Szczecinie, Szczecin (2011).

[3] Gucma S., Kotowska I., Ślączka W. (2016): „Wybór lokalizacji terminalu kontenerowego w Świnoujściu", Inżynieria morska i geotechnika, Nr 6/2016; ISSN 0867-4299, str. 366-377.

[4] Gucma S. i inni (2015): „Morskie drogi wodne. Projektowanie i eksploatacja w ujęciu inżynierii ruchu". Wydawnictwo: Fundacja Promocji Przemysłu Okrętowego i Gospodarki Morskiej, Gdańsk 2015, stron 551, ISBN 978-8360584-51-4.

[5] Gucma S., Ślączka W., Zalewski P. (2013): Parametry torów wodnych i systemów nawigacyjnych wyznaczane przy wykorzystaniu kryteriów bezpieczeństwa nawigacji. Wydawnictwo Naukowe Akademii Morskiej w Szczecinie, Szczecin 2013, stron 96, ISBN 978-83-89901-82-8.

[6] Koncepcja obsługi kontenerowców w Porcie Szczecin i Świnoujście w aspekcie realizacji celów strategii rozwoju portów morskich w Szczecinie i Świnoujściu do roku 2027: (Część I: Analiza nawigacyjna Terminalu Kontenerowego w Porcie Zewnętrznym Świnoujście i wybór optymalnej lokalizacji. - wykonawca AMSz). (Część II: Analiza technicznoeksploatacyjna Terminalu Kontenerowego w Porcie Zewnętrznym Świnoujście. - wykonawca BIMOR). Praca naukowo-badawcza pod kierunkiem S. Gucmy, zlecona przez Ernst \& Young. Akademia Morska w Szczecinie, Szczecin (2015). 
System approach to optimization parameters of the designed marine port...

Systemowe podejście do optymalizacji parametrów projektowanego morskiego...

[7] Projekt systemów zapewniających bezpieczną nawigację i obsługę statków LNG na podejściu i w porcie zewnętrznym w Świnoujściu. Praca naukowobadawcza pod kierunkiem S. Gucmy, zlecona przez Urząd Morski w Szczecinie. Akademia Morska w Szczecinie, Szczecin (2012).

[8] SANDIA (2004): Guidance on Risk Analysis and Safety Implications of a Large Liquefied Natural Gas (LNG) Spill Over Water.

[9] Wstępne oszacowanie parametrów technicznych północnego toru podejściowego do portu w Świnoujściu wraz z szacunkową kalkulacją kosztów. Praca naukowo - badawcza pod kierunkiem W. Ślączki zlecona przez ZPSS. Akademia Morska w Szczecinie (2015).

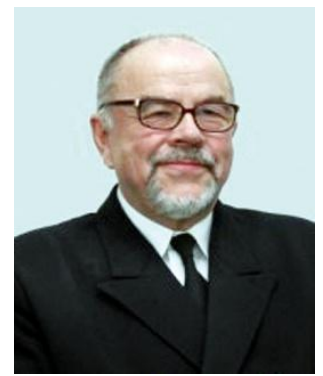

Prof. dr hab. inz. kpt. $\dot{z} . w$. Stanistaw Gucma, Doktor Honoris Causa Państwowego Uniwersytetu Technicznego $\boldsymbol{w}$ Kaliningradzie. jest twórca pierwszej $w$ Polsce szkoty naukowej inżynierii ruchu morskiego $i$ autorem 11 ksiażek oraz ponad 170 publikacji na ten temat. Kierowat ponad 120 projektami naukowymi - wyniki większości z nich zostaty wdrożone $w$ gospodarce Polski oraz innych krajów UE. Prace badawcze profesora Gucmy dotycza m. in. największych inwestycji morskich naszego kraju $n p$. budowy terminalu LNG $w$ Świnoujściu czy przebudowy wejścia do portów $w$ Kolobrzegu i Łebie. Jest czlonkiem Komitetu Transportu PAN, Akademii Inżynierskiej w Polsce oraz Komitetu Transportu Rosji. 